\title{
CONSTRUÇÃO E INSPIRAÇÃO EM POEMAS DE PAULO HENRIQUES \\ BRITTO
}

\section{CONSTRUCTION AND INSPIRATION IN PAULO HENRIQUES BRITTO'S POEMS}

Cristiane Rodrigues de SOUZA ${ }^{10}$

RESUMO: Por meio do estudo do grupo de poemas "Fisiologia da composição", do livro Macau (2003), de Paulo Henriques Britto, é possível perceber a oscilação existente entre a retomada da maneira racional de se estruturar poemas e o espraiar-se subjetivo, já que o eu poético é elaborado por meio do equilíbrio instável entre o eu construído e a expressão da subjetividade empírica, tornando-se, assim, voz representativa da época contemporânea.

PALAVRAS-CHAVE: Poesia brasileira contemporânea; Paulo Henriques Britto; João Cabral de Melo Neto.

ABSTRACT: To study "Fisiologia da composição", from the book Macau, written by Paulo Henriques Britto in 2003, allow us to notice the oscillation between the rational manner of writing verses and the subjective spreading. As the lyric person is elaborated by the instable equilibrium between the lyric mask and the empiric subjective, it is representative of the contemporary time.

KEYWORDS: Brazilian contemporary poetry; Paulo Henriques Britto; João Cabral de Melo Neto.

\footnotetext{
${ }^{10}$ Professora de Teoria da Literatura e de Literatura Brasileira do Centro Universitário Barão de Mauá CEP 14020-380 - Ribeirão Preto - SP - Brasil - E-mail: crika_rodrigues@ hotmail.com
} 
Paulo Henriques Britto, poeta, tradutor, ensaísta e professor de Letras da PUCRio, tem se revelado voz consistente em meio à produção contemporânea. Tendo iniciado a publicação de seus poemas por meio do lançamento do livro Liturgia da matéria, de 1982, publicou depois Mínima lírica (1989), Trovar claro (1997) e Macau (2003), além de contos reunidos em Paraísos artificiais (2004) e de inúmeras traduções, lançando, em 2007, seu mais recente livro de poemas, Tarde, em que repensa sua produção poética.

Em depoimento à revista Ipotesi, em que aparecem misturadas suas faces de crítico e de poeta, Paulo Henriques discorre sobre a relação entre a construção do eulírico e a subjetividade real do escritor, desvelando, ao fazer isso, a consciência da coexistência, em sua obra, da prática racional de se engenhar versos e da presença, muitas vezes negada ou relativizada, da inspiração.

Ao discorrer sobre seu percurso literário, o poeta lembra que, entrando em contato com as ideias do movimento concretista, ao descobrir que, para eles, a poesia como expressão pessoal era considerada resquício de romantismo ultrapassado, deparou-se com obstáculo irremovível à sua produção lírica, já que "se [sua] poesia tinha um projeto, ele era justamente esse [...], a descoberta e a manifestação (ou, como eu diria hoje, a construção) de uma identidade subjetiva" (BRITTO, 2008, p. 12).

O eu-lírico, para Paulo Henriques Britto, é fruto de construção. No entanto, diferente de certa leitura que se tornou comum fazer a partir das ideias de João Cabral de Melo Neto, para ele "criar uma obra poética é muito diferente de projetar uma obra de engenharia" (BRITTO, 2008, p. 14).

O sujeito lírico é um construto, uma ficção elaborada pelo poeta não apenas para escrever poemas, mas para enfrentar certos problemas de sua vida, atendendo a determinadas necessidades emocionais suas. Ela faz parte da construção da personalidade maior do poeta. (BRITTO, 2008, p. 14).

De acordo com Britto, na década de 50, em reação a posturas neossimbolistas da geração de 45, o poeta passa a ser visto como engenheiro ou arquiteto, procurando-se evitar, assim, a presença da subjetividade na produção literária. Dessa forma, ao seguir- 
se a linha de um pretenso antilirismo cabralino, busca-se estabelecer uma ideia de sujeito lírico adequada à época concretista. No entanto, no momento atual, já com maior distanciamento da época citada, Paulo Henriques (2008, p. 16) pode afirmar que "é fácil perceber a transparência do disfarce sob o qual se protegeu a poderosa subjetividade de João Cabral de Melo Neto.” Ademais,

A negação do sujeito lírico em Cabral pode ser vista como um gesto supremo de afirmação da subjetividade. $O$ poetaengenheiro, em última análise, constrói sua personalidade através da estratégia de negar que o faz, e ao criticar as posturas que considera anacrônicas por ainda se preocuparem com as questiúnculas da subjetividade está apenas afirmando, ainda que às avessas, mais uma variedade de construção de sujeito. (BRITTO, 2008, p. 16).

Dessa forma, consciente de que o sujeito lírico não está identificado totalmente com o ser empírico do poeta, mas certo também de que não pode ser tomado da maneira como o faz Foucault, que o vê como o "nome que distingue e caracteriza um determinado corpus textual" (BRITTO, 2008, p. 15), Britto (2008, p. 15) define o eulírico como "um aspecto da personalidade da pessoa que escreve o texto poético construído em função da elaboração desse texto."

Como afirma Luis Bueno (2004, p. 139-140), em resenha sobre Macau, o título desta obra, fazendo referência ao lugar "ao mesmo tempo estranho, pois fica do outro lado do mundo, e familiar, já que partilha conosco a língua e parte de uma história”, aponta para o espaço que é "símbolo do território mínimo e inescapável do eu: um eu que, condenado à própria subjetividade, só se realiza quando se dirige ao mundo [...] por meio da 'fala esquisita' de uma poesia que procura um leitor" (2004, p. 139-140).

No grupo de poemas "Fisiologia da composição", do livro Macau (2003), ao retomar a Psicologia da composição, de Cabral, que remete, por sua vez, ao ensaio "A filosofia da composição", de Edgar Allan Poe, o poeta se insere em uma tradição, reformulando-a, já que, por meio de poemas metalinguísticos, é revelado um sujeito lírico que, apesar de construído racionalmente, ao mesmo tempo é a expressão da 
subjetividade do poeta. Dessa forma, a produção poética do escritor contemporâneo carioca fica entre a reatualização da maneira racional de se estruturar poemas e o espraiar-se da intuição como força motivadora da criação literária.

Ao utilizar o termo "fisiologia", para dar título ao grupo de poemas, Henriques deixa de ver a reflexão sobre a própria poesia como estudo que tende a reunir uma ordem determinada de conhecimentos em um número reduzido de princípios que lhe servem de fundamento, como fez Poe, ao enumerar os preceitos da composição poética. A mudança do termo mostra também a não-completa adesão à forma cabralina de perceber os fenômenos internos - a psicologia - da composição poética. Ao contrário, ao inaugurar a fisiologia da composição, Britto revela entender o ato criador como parte das funções orgânicas - da natureza física ou moral - do ser.

$\mathrm{Na}$ "Fábula de Anfion", que precede a "Psicologia da composição", de João Cabral, a realidade despida de sentimentos e de subjetividade, descontaminada e pura, é desejada pelo poeta, que, como afirma Secchin (1985, p. 52; grifo do autor), "em seu percurso de depuração, [...] via Anfion, vincula a poesia ao sinal de menos; aguça o combate contra o excesso", elegendo como espaço, para tanto, a paisagem seca do deserto.

\author{
(Ali, é um tempo claro \\ como a fonte \\ e na fábula.
}

\author{
Ali, nada sobrou da noite \\ como ervas \\ entre pedras.
}
Ali, é uma terra branca
e ávida
como a cal.
Ali, não há como pôr vossa tristeza como a um livro


na estante).

(MELO NETO, 1986, p. 322).

Como afirma Secchin, nessas estrofes,

João Cabral identifica o orgânico (vegetal) ao noturno, e o inorgânico ao diurno. O vegetal [...] é visto como resquício de uma herança noturna [...] e, assim, deve ser eliminado, em busca de uma 'terra branca', sintagma que reforça o vínculo entre o inorgânico e o diurno. (SECCHIN, 1985, p. 53; aspas do autor).

O eu-lírico cabralino, no entanto, defronta-se com os golpes que o acaso desfere, criando, de forma inesperada, as brechas por meio das quais se insinua a sua subjetividade, assim como o soar da flauta de Anfion faz surgir Tebas, diferente da cidade desejada por ele.

Esta cidade, Tebas, não a quisera assim de tijolos plantada, que a terra e a flora procuram reaver $[\ldots]$

Desejei longamente liso muro, e branco, puro sol em si

(MELO NETO, 1986, p. 326).

O esforço de dominar a flauta da intuição, "cavalo solto, que é louco" (MELO NETO, 1986, p. 327), percorre os versos da "Psicologia da composição", em que é almejada a "forma atingida/ como a ponta do novelo/ que a atenção, lenta,/ desenrola" (MELO NETO, 1986, p. 330). 
Paulo Henriques Britto, no entanto, ao fundar sua "Fisiologia da composição", não tenta domar a inspiração, como Cabral, ou relegá-la a um plano secundário, como fez Poe. Nos versos do poeta contemporâneo, o ímpeto subjetivo coexiste com a estrutura poética forjada racionalmente, atitude confirmada pelo título do grupo de poemas que aponta a existência da forma orgânica da intuição, em meio à construção poética de uma nova Tebas.

\section{FISIOLOGIA DA COMPOSIÇÃO}

\section{I}

A opacidade das coisas

e os olhos serem só dois.

A compulsão sem culpa

de dar sentido a tudo.

O incômodo pejo

de ser só desejo.

Por fim o acaso.

Sem o qual, nada.

(BRITTO, 2003, p.13).

O poeta anuncia, no primeiro poema da "Fisiologia da composição", a necessidade de desvelar o que vai além dos olhos, a saber, o mundo essencial. Dessa forma, Paulo Henriques deseja ultrapassar o fazer poético mineral de Cabral, que busca "as flores e as plantas/, as frutas, os bichos [minerais]/ quando em estado de palavra" (MELO NETO, 1986, p. 331), reatualizando, até certo ponto, o fazer poético instaurado no Romantismo, já que se mostra insatisfeito com a barreira opaca formada pelo mundo empírico, buscando sua transposição.

No entanto, ao mesmo tempo, como se pode perceber por meio da segunda estrofe, o poeta pretende ordenar racionalmente sua percepção do mundo - "dar sentido 
a tudo" (BRITTO, 2003, p. 13) -, buscando a significação e a razão de ser de todas as coisas. Necessidade que, apesar de racional, é movida pelo ato irracional e instintivo da compulsão.

A essa oscilação vem juntar-se a vergonha de saber-se tomado pelo desejo, próprio da poesia romântica, mostrando-se o poeta rendido a impulsos instintivos que instauram o querer.

Por meio de dísticos incisivos que diminuem gradativamente de tamanho, de estrofe em estrofe, formadas, as três primeiras, por 7, 6 e 5 sílabas métricas e, a última, por um verso com 5 e outro com 4 sílabas métricas, o poema, num decrescendo, vai se acercando do silêncio, momento em que é anunciado o acaso como o responsável por tudo - "sem o qual, nada" -, inclusive pelo fazer poético. Dessa forma, na "Fisiologia da composição", o poeta coloca em lugar de destaque o acaso, temido por Cabral por fundar uma Tebas incontrolável, repleta de vida não mineral - na "Fábula de Anfion", no meio totalmente árido, "no deserto, [...] lavado/ de todo canto,/ em silêncio [...] depara/ o acaso, Anfion" (MELO NETO, 1997, p. 56). Não negando a casualidade, Henriques, ao contrário, a torna parte de seu fazer poético, ao lado do trabalho formal da fatura dos versos.

\section{II}

‘A quem possa interessar'? Por aí não se chega jamais a parte alguma.

O impulso é de outra espécie: uma pressão que vem de dentro, e incomoda. No fundo

é só isso que importa. O resto é o resto.

E no entanto nesse resto está o múnus

público da coisa - vá lá o termo -

o que dá trabalho, o que impõe um custo

sem benefício claro à vista, e às vezes 
acaba interessando até quem nunca

se imaginou como destinatário

de uma - digamos assim - 'carta ao mundo',

que é o que a coisa acaba sendo e tendo sido

desde o começo. Como sempre. Como tudo.

(BRITTO, 2003, p.14; aspas do autor).

No segundo poema do grupo, apesar de enfatizar a força que a inspiração e a necessidade de criar poesia imprimem no ser do poeta, vistas como o canto irreprimível de galo, para lembrar Gullar, ou "uma pressão/ que vem de dentro, e incomoda", como afirma Henriques, o poeta, de forma reticente, introduz a discussão sobre o aspecto racional de se moldar versos, que também participa do fazer lírico. Após afirmar que o "impulso" é o que importa e de deixar a elaboração racional do artífice relegada ao plano dos restos, Henriques reconhece que na lida trabalhosa com a palavra está o “múnus/ público da coisa”, expressão garimpada pelo tradutor acostumado ao uso de dicionários, que, antecedida do popular "vá lá o termo", como que reconhecendo o seu desuso na língua corrente, remete àquilo que procede da autoridade pública ou da lei e obriga o indivíduo a certos encargos em benefício da coletividade ou da ordem social. Dessa forma, apesar de reconhecer a força fisiológica que rege a composição poética, Britto não deixa esquecer que o ofício de construtor de versos exige o trabalho com a forma, única maneira de constituir a "carta ao mundo" que é a poesia - "que é o que a coisa acaba sendo e tendo sido/ desde o começo. Como sempre. Como tudo" conclusão afirmada em solene e pausado verso alexandrino que finaliza o poema após a série de decassílabos entoados dentro de ritmo prosaico, apesar da metrificação rígida. Solenidade que revela, pesarosamente, que os resquícios do impulso, portanto, são a única coisa com que pode contar o leitor de poesia.

III

Também os anjos mudam de poleiro de vez em quando, se rareia o alpiste 
indeglutível que é seu alimento.

Porém você não se conforma, e insiste, procura em vão possíveis substitutos que tenham o efeito de atrair de volta

esses seres ariscos, esses putos que se recusam a ouvir os teus apelos, como se fossem mesmo coisas outras que não tua própria vontade de tê-los sempre a postos, em eterna prontidão, a salpicar na tua boca ávida

o alpiste acre-doce da (com perdão da péssima palavra) inspiração.

(BRITTO, 2003, p. 15).

Após ter constatado a importância do trabalho com a estrutura formal, no segundo poema do grupo, Paulo Henriques, mostra, no terceiro texto, a sensação de falta que acomete o poeta, se do poleiro próximo a ele se mudam os anjos responsáveis por salpicar na sua boca ávida os grãos de inspiração - o impulso lírico. Apesar de ter afirmado, no poema anterior, que o ímpeto poético nasce arbitrariamente, como pressão interna no ser de quem escreve, no terceiro poema, Henriques mostra como fica ávida de fome a boca do poeta se nela faltar "o alpiste acre-doce [...] da inspiração". Ao revelar a busca frenética pelo lirismo efetuada pelo poeta, o poema mostra que ele se esquece de que é a sua própria vontade de ter os anjos por perto a responsável por salpicar em sua boca o alimento poético (a inspiração) - de sabor ácido e ativo e, ao mesmo tempo, de gosto doce e meigo. Conjugando contrários, a inspiração, apesar de ser considerada uma "péssima palavra", já que remete ao ato de inspirar, como se fosse algo alheio, o ar da criação poética, é, antes, a completude presente já no próprio ser do poeta. 
Assim, apesar de escrever sob a égide de Cabral e de Poe, Paulo Henriques reelabora, por meio de sua "Fisiologia da composição", a maneira de pensar o fazer poético dos dois escritores, constituindo-se como voz representativa da contemporaneidade na medida em que mantém sobrepostas a inspiração e a técnica artística, em um equilíbrio instável. Como diz Marcos Siscar (2008, p. 215), há em Paulo Henriques "uma espécie de renúncia à experiência libertadora contida na utopia da singularidade" (renúncia à liberdade total formal), sendo que, para ele, "a forma está [...] no acontecimento da crise, na irritação do entrelugar." O poeta realiza, portanto, o que Carlos Reis (2003, p. 292) afirma ser "a possibilidade de inovar pelo interior da tradição."

IV

A coisa e o avesso. Assim:

preto $=$ branco. Nada

só o que é: também o contrário,

o não tanto quanto o sim,

a solução e a charada.

É um método arbitrário,

decerto, escolhido a esmo.

Porém não tem como errar.

No fim (no início, pois)

dá exatamente no mesmo:

bem aqui neste lugar,

o de antes (ou depois),

onde as coisas param (andam).

Q. E. D.

(BRITTO, 2003, p. 16). 
Ao tentar encontrar uma fórmula matemática que una contrários, como os apresentados nos poemas anteriores, a saber, técnica e inspiração, Henriques retoma solução encontrada por Mário de Andrade ao falar sobre poesia, em seu "Prefácio interessantíssimo", quando afirma que "arte [...] somada a Lirismo, dá Poesia" (ANDRADE, 1993, p. 63), fazendo referência a pensamento de Paul Dermée. Como o poeta carioca valoriza a intuição tanto quanto a técnica, diferente do Cabral da "Psicologia da composição", coloca-se, portanto, ao lado de Mário, que buscava evitar, primeiro, que a técnica impedisse o livre curso do lirismo, "nascido no subconsciente"; depois, reconhecendo o valor do lapidar artístico - "Arte é moldar mais tarde o poema de repetições fastientas, de sentimentalidades românticas, de pormenores inúteis ou inexpressivos." (ANDRADE, 1993, p. 63).

Paulo Henriques procura, por meio do quarto poema do grupo, estabelecer a equação que defina a medida da coexistência dos contrários - inspiração e técnica. No entanto, a fórmula do poeta contemporâneo é arbitrária e, por isso, não é imposta como regra, mostrando-se, antes, dependente da vontade do poeta - "É um método arbitrário,/ decerto, escolhido a esmo" (BRITTO, 2003, p. 16). Além disso, ao mesmo tempo em que a constrói, Paulo Henriques a desconstrói, ao mostrar de forma bem humorada os paradoxos a que levaria se fosse tomada como norma - "No fim (no início, pois)/ dá exatamente o mesmo:/ bem aqui neste lugar,/ o de antes (ou depois)".

A expressão latina Quod erat demonstrandum - "Como se queria demonstrar", normalmente citada ao fim de argumentação filosófica ou de demonstração de raciocínio matemático - , ao fechar o poema, reforça o tom de brincadeira que o percorre, pois ridiculariza a redução do entendimento da arte a fórmulas científicas. A crítica a esse modo de entender poesia torna-se aparente por meio do verso "não tem como errar", que, retomando expressão popular - "não tem erro" -, normalmente usada para se minimizar a impressão de que algo errado pode acontecer, introduz no poema a percepção de que, diferente do que se afirma, pode-se incorrer em erro ao seguir literalmente instruções dadas. Além disso, a expressão evidencia o ridículo de se pretender estabelecer um roteiro infalível para a execução poética.

É preciso que haja uma estrutura, 
uma coisa sólida, consistente,

artificial, capaz de ficar

sozinha em pé (não necessariamente

exatamente na vertical), dura

e ao mesmo tempo mais leve que o ar,

senão não sai do chão. E a graça toda

da coisa, é claro, é ela poder voar,

feito um balão de gás, e sem que exploda

na mão, igual a um fogo de artifício

que deu chabu. Não. Tem que ser na altura

de um morro, no mínimo, ou de um míssil

terra-a-ar. Sim. Menos arquitetura

que balística. É claro que é difícil.

(BRITTO, 2003, p. 17).

Após ter oscilado entre o valor da técnica e da inspiração, nos textos da "Fisiologia", Paulo Henriques finaliza seu grupo de poemas mostrando a poesia como forma sustentada por estrutura "sólida, consistente", como as palavras-minérios de Cabral, sendo "artificial", ou seja, moldada pela técnica do poeta, além de ser dura e pesada o suficiente para resistir ao tempo, mas leve o bastante para que possa voar. $\mathrm{O}$ voo deve ser dado por ímpeto subjetivo que surge no eu poético, mas comedido, não exacerbado, como fora o romântico, arriscado a explodir na mão feito fogo de artifício. É preciso antes um impulso capaz de sustentar no ar a estrutura poética, como balão de gás. Dessa forma, o eu-lírico deve buscar a medida exata do poema: nem ímpeto exagerado, que exploda, nem tanto peso, que não voe, criando o efeito lúdico do balão elevando-se no ar, imagem que reescreve o poema apresentado em "Tecendo a manhã", de Cabral.

Ao dar o tamanho do voo poético, Henriques o faz medindo-o pela altura de um morro, pelo menos, ou do trajeto capaz de ser efetuado por um projétil que sai da terra 
ao ar. Essa última imagem define bem sua concepção de poesia, feita não tanto por meio de arquitetura, equilíbrio entre a força de gravidade e a sustentação de edifícios, mas por balística, ciência que estuda os movimentos dos projéteis - qualquer sólido pesado que se move no espaço, abandonado a si mesmo depois de haver recebido impulso.

\section{REFERÊNCIAS}

ANDRADE, M de. Poesias completas. Edição crítica de Diléa Zanotto Manfio. Belo Horizonte: Villa Rica, 1993.

BRITTO, P. H. Macau. São Paulo: Companhia das Letras, 2003.

Poesia: criação e tradução. Ipotesi, Juiz de Fora, v. 12, n. 2, p. 11-17, jul./dez. 2008 .

BUENO, L. Poesia e assunto. Revista de Letras, Curitiba, n. 62, p. 139-143, jan./abr. 2004.

MELO NETO, J. C. de. Poesias completas. Rio de Janeiro: J. Olympio, 1986. Psicologia da composição. In: Serial e antes. Rio de Janeiro: Nova Fronteira, 1997. p. 51-69.

REIS, C. O conhecimento da literatura. Porto Alegre: EDIPUCRS, 2003.

SECCHIN, A. C. João Cabral: a poesia do menos. São Paulo: Duas Cidades; Brasília: INL/Fundação Nacional Pró-Memória (MEC), 1985.

SISCAR, M. Poetas à beira de uma crise de versos. In: PEDROSA, C; ALVES, I.

(Org.). Subjetividades em devir. Rio de Janeiro: 7Letras, 2008.

POE, E. A. A filosofia da composição. In: Poemas e ensaios. Tradução Oscar Mendes e Milton Amado. São Paulo: Globo, 1999. p. 101-112.

Artigo recebido em 03/05/2010. Aceito para publicação em 08/06/2010. 